\title{
Forecasting of Black Pepper Price in Karnataka State: An Application of ARIMA and ARCH Models
}

\author{
H.B. Mallikarjuna ${ }^{1 *}$, Anupriya Paul ${ }^{1}$, Ajit Paul ${ }^{1}$, Ashish S. Noel ${ }^{2}$ and M. Sudheendra ${ }^{3}$ \\ ${ }^{1}$ Department of Mathematics and Statistics, ${ }^{2}$ Department of Agricultural Economics, \\ SHUATS, Allahabad, India \\ ${ }^{3}$ Department of Agriculture Extension, College of Agriculture, UAHS, Shivamogga, India \\ *Corresponding author
}

\section{Ke y w o r d s \\ Forecasting, Price, Black Pepper, ARIMA, ARCH, GARCH \\ Article Info \\ Accepted: \\ 12 December 2018 \\ Available Online: \\ 10 January 2019}

\section{A B S T R A C T}

The study was conducted to forecast the price of black pepper in one of the major markets of Karnataka state as the state ranks first position in production of pepper in India. The Gonikoppal market in Kodagu district was selected purposively on the basis of highest area and production in the state. The monthly prices of black pepper in Gonikoppal market were collected from the Karnataka State Agricultural Marketing Board, Bangalore, Karnataka state for the year 2008-09 to 2017-18. The time-series models such as ARIMA and ARCH models were applied to price data using software's such as SPSS, Gretl and EViews. The Augmented Dickey-Fuller test and Heteroscedasticity Lagrange's Multiplier test were used to test the stationarity and volatility of the time-series respectively. The best forecasted model was determined based on the lowest values of Akaike's Information Criterion (AIC) and Schwartz Bayesian Information Criterion (SBIC). However, the predictability power, performance and quality of the model was measured based on the lowest error value of the Root Mean Square Error (RMSE) and Mean Absolute Prediction Error (MAPE). Among the tested models the prediction accuracy of the ARIMA model was higher than ARCH family models. On the basis of the results, the ARIMA $(0,1,1)$ provide a good fit for forecasting the price of black pepper.

\section{Introduction}

Black pepper is an important spice crop in the Karnataka state. The analysis of price over time is important for formulating a sound agricultural price policy. Agricultural prices give the signal to both producers and consumers regarding the level of production and consumption. Changes in the relative prices of the various agricultural commodities affect the allocation of resources among agricultural commodities by the producers. Agricultural price movements have been a matter of serious concern for policy makers in our country as the behaviour of agricultural prices adversely affects the steady economic development. Among other things, price plays a strategic role in influencing the cultivation of pepper. Indeed, the price analysis of pepper assumes greater significance not only to the 
policy makers but also to producers and consumers. The black pepper prices have been highly fluctuating over the years. An increase in price of pepper affects the consumer by way of increase in food consumption budget, while a decrease in pepper prices below the cost of cultivation affects the producer. No studies have been conducted on forecasting the price of black pepper so far. In this context, it is necessary to know to what extent the prices are being fluctuated and to draw meaningful policy conclusion. Hence, the study focuses on the objective to forecast the black pepper price by using various time-series models.

Bhardwaj et al., (2014) applied the ARIMA models and GARCH models for forecasting the spot prices of Gram at Delhi market. They were procured the secondary data for a period of 01 January 2007 to 19 April 2012 from NCDEX website. The AIC and SIC values from GARCH model were smaller than that from ARIMA model. Therefore, the GARCH $(1,1)$ model was found better model in forecasting spot price of Gram.

Seyed Jafar Sangsefidi et al., (2015) applied the ARIMA models and GARCH models for forecasting the prices of agricultural products, including potato, onion, tomato and veal. The results of the ARIMA model and ARCH models were compared. The results showed that the estimation due to ARIMA method has less relative error than the estimation through the ARCH model. The ARIMA model outperformed than ARCH model.

Naveena (2016) studied the various time series models for forecasting of price and export of Indian coffee. In his study, the forecasting models like Exponential Smoothing, Autoregressive Integrated Moving Average (ARIMA), Generalized Auto Regressive Conditional Heteroscedastic (GARCH) and Artificial Neural Network (ANN) models were developed for price and export study.
The RMSE and MAPE were used to assess the reliability of the various forecasting models. The results showed that ARIMA $(0,1,1)(0,0,0)$ model is best for Indian Arabica price, AR(3)GARCH $(3,1)$ models were best for Robusta coffee price and for Indian coffee export ANN model performed better than others.

Verma et al., (2016) studied the forecasting of coriander prices in Rajasthan by using ARIMA models. To test the reliability of models AIC, BIC and MAPE were used. On comparing the alternative models, it was observed that AIC (2141.14), BIC (2147.09) and MAPE (6.38) were least for ARIMA $(0,1,1)$ model, hence it is best model. Therefore it was observed that most representative model for the price of coriander in Ramganjmandi of Rajasthan.

\section{Materials and Methods}

The study was conducted to forecast the price of black pepper in Gonikoppal market of Kodagu district, Karnataka state, where the district was selected based on highest area and production. The secondary data pertaining to monthly price (in Rs./Quintal) of black pepper for the period of 2008-09 to 2017-18 were collected from Karnataka State Agricultural Marketing Board (KSAMB), Bangalore, Karnataka State. To forecast the price, the ARIMA and ARCH models have been used which are linear and non-linear models respectively.

\section{ARIMA models}

The ARIMA stands for Autoregressive Integrated Moving Average. This technique is used to forecast future values of a time-series based on completely its own past values. The first thing is to note that, most of the timeseries are non-stationary and the ARIMA model refers only to a stationary (Box et.al. 2015). The ARIMA models are the 
combinations of the autoregressive (AR), integration (I) - referring to the reverse process of differencing to produce the forecast and moving average (MA) operations. An ARIMA model is usually stated as ARIMA (p, $d$, q). This represents the order of the autoregressive components (p), the number of differencing operators (d) and the highest order of the moving average terms (q).

The simplest example of a non-stationary process which reduces to a stationary one after differencing is random walk. A process $\left\{y_{t}\right\}$ is said to follow an Integrated ARMA model, denoted by ARIMA (p, d, q), if $\nabla^{\mathrm{d}} \mathrm{y}_{\mathrm{t}}=(1-\mathrm{B})^{\mathrm{d}} \varepsilon_{\mathrm{t}}$ is $\operatorname{ARMA}(\mathrm{p}, \mathrm{q})$.

The model is written as $\varphi(\mathrm{B})(1-\mathrm{B})^{\mathrm{d}} \mathrm{y}_{\mathrm{t}}=\theta(\mathrm{B}) \varepsilon_{\mathrm{t}}$

where $\varepsilon_{\mathrm{t}} \sim \mathrm{WN}\left(0, \sigma^{2}\right), \mathrm{WN}$ indicating White Noise. The integration parameter $d$ is a nonnegative integer. When $\mathrm{d}=0, \operatorname{ARIMA}(\mathrm{p}, \mathrm{d}$, q) $\equiv \operatorname{ARMA}(p, q)$.

The main stages in setting up an ARIMA forecasting model are: Identification of models, estimating the parameters, diagnostic checking and forecasting.

\section{Identification of Models}

A good starting point for time series analysis is a graphical plot of the time-series. The foremost step in the process of modeling is to check for the stationarity of the series, as the estimation procedures are available only for stationary series. We can use Augmented Dickey-Fuller (ADF) test or Unit root test to check stationarity in the time-series, where the null hypothesis is that, there is a unit root or the time series under consideration is nonstationary. If the value of $\mathrm{p}$ is greater than 0.05 we have to accept the null hypothesis, then the hypothesis is tested by performing appropriate differencing of the data in $\mathrm{d}^{\text {th }}$ order and applying the ADF test to the differenced time series data, until reject the null hypothesis. Another way of checking the stationarity is estimated with Autocorrelation Function (ACF) and Partial Autocorrelation Function (PACF). If ACF decay towards zero and PACF has significant spike at first lag which indicates series is non-stationary. If $\mathrm{ACF}$ and PACF spikes becomes abruptly cut off to zero which indicates series is stationary. The nonstationary time-series can be converting into stationary by differencing the original series using difference technique.

For the stationary series, the tentative models were identified based on examination of the ACF and PACF. The minimum Akaike's Information Criterion (AIC) and Schwartz Bayesian Information Criterion (SBIC) are used to select the best model from the set of tentative models.

$\mathrm{AIC}=-2 \log (\mathrm{L})+2 \mathrm{~m}$

SBIC $=-2 \log (\mathrm{L})+\mathrm{m} \log (\mathrm{n})$

where, $\mathrm{L}=$ Maximum Likelihood, $\mathrm{m}=$ No. of parameters, $\mathrm{n}=$ No. of observations,

\section{Estimation of parameters}

Using the Maximum Likelihood Estimation (MLE) method, the parameters of the selected model with standard error are estimated (Fan and Yao, 2003).

\section{Diagnostic checking}

After having the estimated parameters of a selected model, it is necessary to do diagnostic checking to verify that the model is adequate or not. If the model is found to be statistically inadequate the whole process of identification, estimation and diagnostic checking is repeated until a suitable model is found. To know the goodness of the fitted model we can use 
various methods like, ACF and PACF plots of residuals, histogram of residuals, normality QQ plot of residuals and Ljung-Box ' $Q$ ' statistic for residuals. The Ljung-Box ' $Q$ ' statistic is distributed approximately as a Chi-square statistic. If the $\mathrm{p}$-value associated with the ' $\mathrm{Q}$ ' statistic is large $(\mathrm{p}>0.05)$, then the model is considered adequate.

\section{Forecasting}

The accuracy of forecasts was tested using Root Mean Square Error (RMSE) and Mean Average Percentage Error (MAPE). Lastly, the final model is used to generate the predictions about the future values.

\section{ARCH family models}

If the time-series consist volatility, the variance changes through time, thus study uses Autoregressive Conditional Heteroscedasticity $(\mathrm{ARCH})$ family models. If there is a volatility or ARCH effect in the time-series, we can run the $\mathrm{ARCH}$ family models viz., ARCH, GARCH, EGARCH and TGARCH models.

\section{ARCH model}

The most promising parametric non-linear time series model is Autoregressive Conditional Heteroscedasticity (ARCH) model. It was one of the first models that provided a way to model conditional heteroscedasticity in volatility. The $\mathrm{ARCH}$ model allows the conditional variances to change over time as a function of squares past errors leaving the unconditional variance constant. The $\operatorname{ARCH}(\mathrm{q})$ model for the series $\left\{\varepsilon_{t}\right\}$ is defined by specifying the conditional distribution of $\varepsilon_{\mathrm{t}}$ (error) given the information available up to time $\mathrm{t}-1$.

The ARCH (q) model for the series $\left\{\varepsilon_{\mathrm{t}}\right\}$ is given by

$$
\begin{aligned}
& \varepsilon_{\mathrm{t}}=\sigma^{2}{ }_{\mathrm{t}} \xi_{\mathrm{t}, y} \quad\left\{\xi_{\mathrm{t}}\right\} \sim \text { iid }(0,1) \\
& \sigma_{\mathrm{t}}^{2}=\alpha_{0}+\sum_{\mathrm{i}=1}^{\mathrm{q}} \alpha_{\mathrm{i}} \varepsilon_{\mathrm{t}-\mathrm{i}}^{2}
\end{aligned}
$$

where, $\alpha_{0}>0$ and $\alpha_{\mathrm{i}} \geq 0$, for all $\mathrm{i}$ and $\sum_{i=1}^{q} \alpha_{i}<1$ are required to be satisfied to ensure non-negative and finite unconditional variance of stationary $\left\{\varepsilon_{\mathrm{t}}\right\}$ series.

\section{GARCH model}

The ARCH model has some drawbacks. Firstly, when the order of ARCH model is very large, estimation of a very large number of parameters is required. Secondly, conditional variance of $\mathrm{ARCH}(\mathrm{q})$ model has the property that unconditional autocorrelation function of squared residuals, if exists, decays very rapidly compared to what is typically observed, unless maximum lag $\mathrm{q}$ is large. To overcome these difficulties, the Generalized Autoregressive Conditional Heteroscedasticity (GARCH) model has been developed; in which conditional variance is also a linear function of its own lags. This model is also a weighted average of past squared residuals, but it has declining weights that never go completely to zero. It gives parsimonious models that are easy to estimate and, even in its simplest form, has proven surprisingly successful in predicting conditional variances.

The GARCH (p, q) model for the series $\left\{\varepsilon_{\mathrm{t}}\right\}$ is given by

$$
\varepsilon_{\mathrm{t}}=\sigma_{\mathrm{t}}^{2} \xi_{\mathrm{t}^{y}} \quad\left\{\xi_{\mathrm{t}}\right\} \sim \text { iid }(0,1)
$$

$$
\sigma_{\mathrm{t}}^{2}=\alpha_{0}+\sum_{\mathrm{i}=1}^{\mathrm{q}} \alpha_{\mathrm{i}} \varepsilon_{\mathrm{t}-\mathrm{i}}^{2}+\sum_{\mathrm{j}=1}^{\mathrm{p}} \beta_{\mathrm{j}} \sigma_{\mathrm{t}-\mathrm{j}}^{2}
$$

Where, $\quad \alpha_{0}>0, \quad \alpha_{\mathrm{i}} \geq 0, \quad \beta_{\mathrm{j}} \geq 0 \quad$ and $\sum_{i=1}^{q} \alpha_{i}+\sum_{j=1}^{p} \beta_{j}<1$

Where, $\alpha_{\mathrm{i}} \equiv 0$ for $\mathrm{i}>\mathrm{q}$ and $\beta_{\mathrm{j}} \equiv 0$ for $\mathrm{j}>\mathrm{p}$ 


\section{EGARCH model}

Both the ARCH and GARCH models are able to represent the persistence of volatility, the so-called volatility clustering but both the models assume that positive and negative shocks have the same impact on volatility.

It is well known that for financial asset volatility the innovations have an asymmetric impact. To be able to model this behavior and to overcome the weaknesses of the GARCH model, the first extension to the GARCH model has been developed, called the Exponential GARCH (EGARCH).

The EGARCH model for the series $\left\{\varepsilon_{t}\right\}$ is given by

$\varepsilon_{\mathrm{t}}=\sigma^{2}{ }_{\mathrm{t}} \xi_{\mathrm{t},} \quad\left\{\xi_{\mathrm{t}}\right\} \sim \operatorname{iid}(0,1)$

$\log \left(\sigma_{t}^{2}\right)=\alpha_{0}+\sum_{i=1}^{q}\left[\alpha_{i} \varepsilon_{t-1}+\gamma_{i}\left(\left|\varepsilon_{t-i}\right|-E\left(\left|\varepsilon_{t-1}\right|\right)\right)\right]+\sum_{j=1}^{p} \beta_{j} \log \left(\sigma_{t-j}^{2}\right)$

Here, no restrictions are imposed on the parameters to guarantee a non-negative conditional variance. The EGARCH model is able to model the volatility persistence, mean reversion as well as the asymmetrical effect. To allow for positive and negative shocks to have different impact on the volatility is the main advantage of the EGARCH model compared to the GARCH model.

\section{TGARCH model}

An alternative way of modeling the asymmetric effects of positive and negative of series was presented by Glosten, Jagannathan and Runkle (1993) and resulted so called GJRGARCH model or Threshold GARCH (TGARCH).

The TGARCH model for the series $\left\{\varepsilon_{t}\right\}$ is given by $\varepsilon_{\mathrm{t}}=\sigma^{2}{ }_{\mathrm{t}} \xi_{\mathrm{t}}, \quad\left\{\xi_{\mathrm{t}}\right\} \sim \operatorname{iid}(0,1)$

$\sigma_{t}^{2}=\alpha_{0}+\sum_{i=1}^{q}\left(\alpha_{i} \varepsilon_{t-i}^{2}\left(1-I\left[\varepsilon_{t-1}>0\right]\right)+\gamma_{i} \varepsilon_{t-i}^{2}\left[\varepsilon_{t-i}>0\right]\right)+\sum_{j=1}^{p} \beta_{j} \sigma_{t-j}^{2}$

Where, $\alpha_{0}>0, \quad \alpha_{\mathrm{i}} \geq 0, \quad \beta_{\mathrm{j}} \geq 0, \quad \gamma_{\mathrm{i}} \geq 0$ to guarantee that the conditional variance is nonnegative. The properties of the TGARCH model are very similar to the EGARCH model, where both are able to capture the asymmetric effect of positive and negative shocks.

The following are the main stages in forecasting using ARCH family models: Identification of Models, Estimation of Parameters, Diagnostic Checking and Forecasting

\section{Identification of models}

A good starting point for time series analysis is a graphical plot of the time-series. The foremost step in the process of modeling is to check for the stationarity of the series, as the estimation procedures are available only for stationary series. We can use ADF test to know the presence of stationarity.

If the model is found to be non-stationary, stationary could be achieved by differencing the series. In this step, we have to test the volatility or $\mathrm{ARCH}$ effect in the time-series data using the Heteroscedasticity Lagrange's Multiplier test (Tsay, 2005) or ARCH LM test. In this ARCH LM test, the null hypothesis is that, there is no ARCH effect or volatility. If the value of $\mathrm{p}$ (w.r.t. chi-square) is less than 0.05 , then only we can run ARCH family models for the stationary series, otherwise we cannot.

The minimum AIC and SBIC are used to select the best model from the set of ARCH, GARCH, EGARCH and TGARCH models. 


\section{Estimation of parameters}

At the identification stage one or more models are tentatively chosen that seem to provide statistically adequate representations of the available data. Using the MLE method, the parameters of the selected model with standard error are estimated (Fan and Yao, 2003).

\section{Diagnostic checking}

It is necessary to do diagnostic checking to verify that the selected model is adequate or not. If the model is found to be statistically inadequate the whole process of identification, estimation and diagnostic checking is repeated until a suitable model is found. To know the goodness of the fitted model we can use methods like, Serial Correlation LM test and Normality test for residuals.

The Serial Correlation LM test for residuals is same as that of Heteroscedasticity Lagrange's Multiplier test, but the null hypothesis is that there is no serial correlation in the residuals. If the value of $\mathrm{p}$ (w.r.t. chi-square statistic) is greater than 0.05 , then accept the null hypothesis. In the Normality test for residuals, the null hypothesis is that the residuals are normally distributed. If the value of $p$ (w.r.t. Jarque-Bera statistic) is greater than 0.05, then accept the null hypothesis.

\section{Forecasting}

The accuracy of forecasts was tested using RMSE and MAPE. Lastly, the final model is used to generate the predictions about the future values.

\section{Results and Discussion}

In this study, the time-series models were fitted on price of black pepper. The objective of fitting multiple time series models on the data is to obtain reliable forecasts on the basis of statistical measures.

\section{ARIMA models}

The monthly price data of black pepper in Gonikoppal market for the period from 200809 to 2017-18 were used to choose the ARIMA models for forecasting using Gretl Software.

The upward trend in the price was observed from Figure 1. The plots of ACF and PACF of price are presented in Figure 2; it is observed that the decay rate for the ACF of the timeseries is very low and the PACF abruptly falls down after first lag. This indicates existence of non-stationarity in the time-series. The nonstationary time-series can be converting into stationary by differencing the original series using difference technique. But after differencing of the original series, the decay rate becomes high and price series become stationary (Fig. 3). To this end, ADF test was used to test the stationarity (Table 1), it was found to be non-stationary for level series and stationary for first differenced series. And also it can be observed from the ACF (Fig. 2), there is no significant lag between 1 to 12 lags, which shows the absence of seasonality in the time-series.

From the examination of the ACF and PACF plots of the first differenced time-series, the tentative models were identified, which are presented in Table 2. On basis of minimum AIC (2359.88) and SBIC (2368.22) values, the ARIMA $(0,1,1)$ model is selected as best model among all the tentative models. The parameters of the selected ARIMA $(0,1,1)$ model with standard error were estimated using MLE and presented in Table 3.

Residual analysis was carried out to check the adequacy of the model. The adequacy of the model is judged based on the value of Ljung- 
Box 'Q' statistic. The Q-statistic value (22.726) was found to be non-significant (Table 4) indicating white noise of time-series and also ACF and PACF plots of residuals (Fig. 4), Histogram of residuals (Fig. 5) and Normality Q-Q plot of residuals (Fig. 6) indicates white noise of the time-series. Thus, these results suggest that, the model ARIMA $(0,1,1)$ is adequate. Further, it is confirmed that, in SPSS software, using Expert Modeler option, the ARIMA $(0,1,1)$ model was found to be the best among the ARIMA models.

\section{ARCH family models}

The monthly price data of black pepper in Gonikoppal market for the period from 200809 to 2017-18 were used to choose the ARCH family models for forecasting using EViews Software.

The ADF test was used to test the stationarity (Table 1), it was found to be non-stationary for level series and stationary for first differenced series.

Table.1 Augmented Dickey-Fuller test

\begin{tabular}{|l|c|c|c|c|}
\hline \multirow{2}{*}{ ADF Test } & \multicolumn{2}{|c|}{ Level Series } & \multicolumn{2}{c|}{ First Differenced Series } \\
\cline { 2 - 5 } & Statistic & p-value\# & Statistic & p-value\# \\
\hline None & -0.1725 & 0.6241 & -10.4367 & 0.000 \\
\hline Constant & -1.4290 & 0.5696 & -10.4448 & 0.000 \\
\hline Constant and Trend & -1.7739 & 0.7176 & -10.4815 & 0.000 \\
\hline
\end{tabular}

\# Mackinnon (1996) one sided p values

Table.2 Tentatively identified ARIMA (p,d,q) models

\begin{tabular}{|c|c|c|}
\hline Tentative Models & AIC & SBIC \\
\hline $\mathbf{0 1 1}$ & $\mathbf{2 3 5 9 . 8 8}$ & $\mathbf{2 3 6 8 . 2 2}$ \\
\hline $\mathbf{1 1 0}$ & 2365.08 & 2373.42 \\
\hline $\mathbf{1 1 1}$ & 2360.92 & 2372.04 \\
\hline $\mathbf{0 1 2}$ & 2360.65 & 2371.76 \\
\hline $\mathbf{2 1 0}$ & 2362.31 & 2373.42 \\
\hline $\mathbf{1 1 2}$ & 2362.63 & 2376.53 \\
\hline $\mathbf{2 1 1}$ & 2362.10 & 2375.99 \\
\hline $\mathbf{2 1 2}$ & 2362.24 & 2378.91 \\
\hline
\end{tabular}

Table.3 Estimates of ARIMA $(0,1,1)$ model

\begin{tabular}{|c|c|c|c|c|}
\hline Parameter & Co-efficient & S.E. & z-value & p-value \\
\hline Constant & 222.303 & 260.193 & $0.854^{\text {NS }}$ & 0.392 \\
\hline MA (1) & -0.407 & 0.089 & $-4.542^{*}$ & 0.000 \\
\hline
\end{tabular}

NS: Non-significant

* Significant at $5 \%$ level of significance 
Table.4 Ljung-Box 'Q' statistic for residuals of ARIMA $(0,1,1)$ model

\begin{tabular}{|c|c|c|}
\hline Statistic & DF & p-value \\
\hline $\mathbf{2 2 . 7 2 6}^{\text {NS }}$ & 17 & 0.158 \\
\hline
\end{tabular}

NS: Non-significant

Table.5 Heteroscedasticity LM Test for first differenced

\begin{tabular}{|c|c|}
\hline $\mathbf{N} * \mathbf{R}^{2}$ & Prob. Chi-Square (1) \\
\hline $61.237 *$ & 0.000 \\
\hline
\end{tabular}

Table.6 ARCH Family Models

\begin{tabular}{|l|c|c|}
\hline Models & AIC & SBIC \\
\hline ARCH(1) & 22.39 & 22.47 \\
\hline ARCH(2) & 22.43 & 22.53 \\
\hline GARCH(1,1) & 22.37 & 22.46 \\
\hline EGARCH(1,1) & 22.10 & 22.21 \\
\hline TARCH(1,1) & 22.35 & 22.47 \\
\hline AR(1) ARCH(1) & 22.22 & 21.31 \\
\hline AR(1) ARCH(2) & 21.25 & 21.37 \\
\hline AR(2) ARCH(1) & 21.23 & 21.32 \\
\hline AR(2) ARCH(2) & 21.31 & 21.43 \\
\hline AR(1) GARCH(1,1) & 20.29 & 20.40 \\
\hline AR(2) GARCH(1,1) & 20.55 & 20.66 \\
\hline AR(1) EGARCH(1,1) & $\mathbf{1 8 . 7 2}$ & $\mathbf{1 8 . 8 6}$ \\
\hline AR(2) EGARCH(1,1) & 19.23 & 19.37 \\
\hline AR(1) TARCH(1,1) & 20.29 & 20.43 \\
\hline AR(2) TARCH(1,1) & 20.74 & 20.88 \\
\hline
\end{tabular}

Table.7 Estimates of AR(1)-EGARCH(1,1) Model

\begin{tabular}{|c|c|c|c|c|}
\hline \multicolumn{5}{|c|}{ LOG(GARCH) $=$ C(3) + C(4)*ABS(RESID(-1)/@SQRT(GARCH(-1))) + C(5) } \\
\hline \multirow{5}{|c|}{ *RESID(-1)/@SQRT(GARCH(-1)) + C(6)*LOG(GARCH(-1)) } \\
\hline Variable & Coefficient & Mean Equation \\
\hline Ctd. Error & z-Statistic & Prob. \\
\hline AR(1) & 78191.28 & 30204.85 & 2.588699 & 0.0096 \\
\hline \multicolumn{5}{|c|}{ Variance Equation } \\
\hline C(3) & 0.997188 & 0.000955 & 1044.533 & 0.0000 \\
\hline C(4) & 0.678936 & $4.08 \mathrm{E}-07$ & 1662771. & 0.0000 \\
\hline C(5) & 0.201290 & $6.14 \mathrm{E}-07$ & -327658.2 & 0.0000 \\
\hline C(6) & 0.291574 & 0.034735 & 8.394208 & 0.0000 \\
\hline
\end{tabular}


Table.8 Serial Correlation LM Test for Residuals of AR(1)-EGARCH(1,1) Model

\begin{tabular}{|c|c|}
\hline $\mathbf{N}^{*} \mathbf{R}^{2}$ & Prob. Chi-Square (4) \\
\hline $\mathbf{6 . 8 9 9}^{\mathrm{NS}}$ & 0.141 \\
\hline
\end{tabular}

$\mathrm{N}-$ No. of observations

NS: Non-significant

Table.9 Normality Test for Residuals of AR(1)-EGARCH(1,1) Model

\begin{tabular}{|c|c|}
\hline Jarque-Bera Statistic & Prob. \\
\hline $\mathbf{0 . 7 6 8}^{\mathrm{NS}}$ & 0.681 \\
\hline
\end{tabular}

NS: Non-significant

Table.10 Forecast Evaluation Statistic's

\begin{tabular}{|c|c|c|}
\hline Model fit statistic's & ARIMA (0, 1, 1) & AR(1)-EGARCH(1,1) \\
\hline RMSE & $\mathbf{4 7 7 2 . 1 0}$ & 5070.00 \\
\hline MAPE & $\mathbf{8 . 8 4}$ & 8.88 \\
\hline
\end{tabular}

Fig.1\&2 Time Series Plot \& ACF and PACF Plots of Level Series
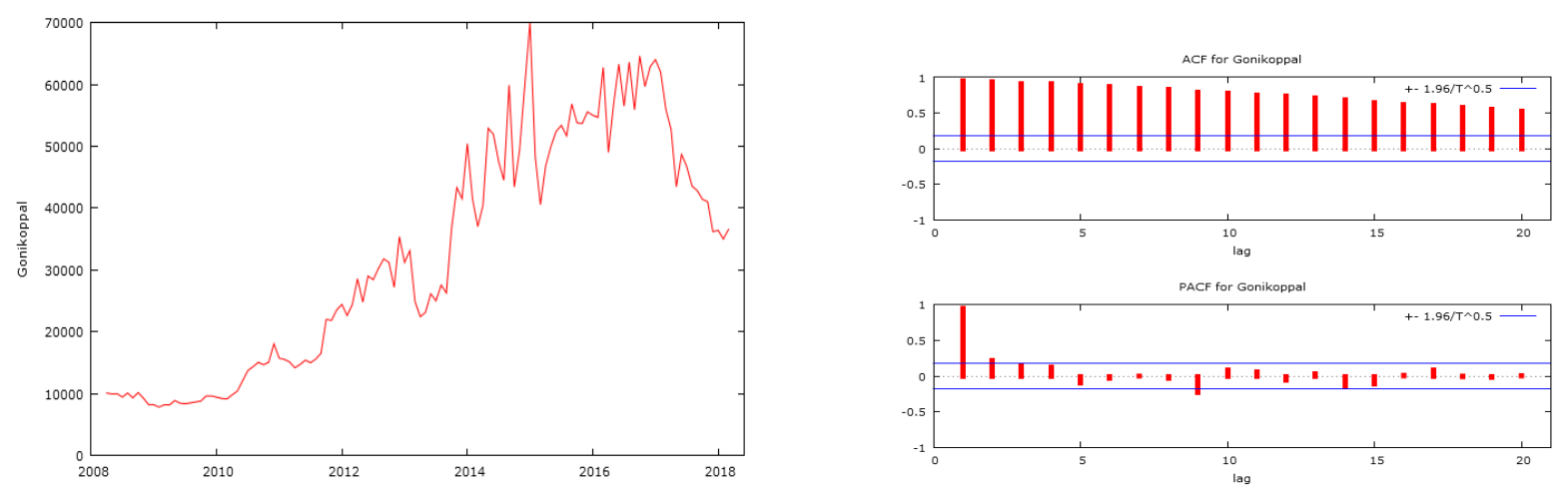

Fig.3\&4 ACF and PACF Plots of First Differenced Series \& ACF And PACF Plots Of Residuals From Arima $(0,1,1)$ Model
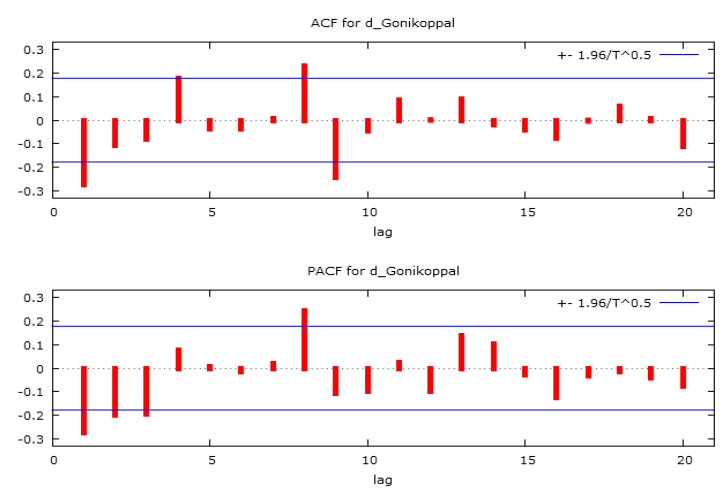
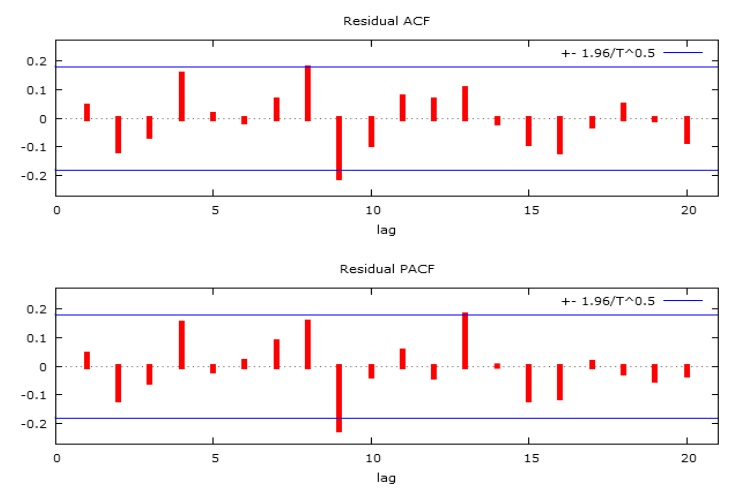
Fig.5\&6 Histogram of Residuals From Arima $(0,1,1)$ Model \& Normality Q-Q Plot Of Residuals From Arima $(0,1,1)$ Model
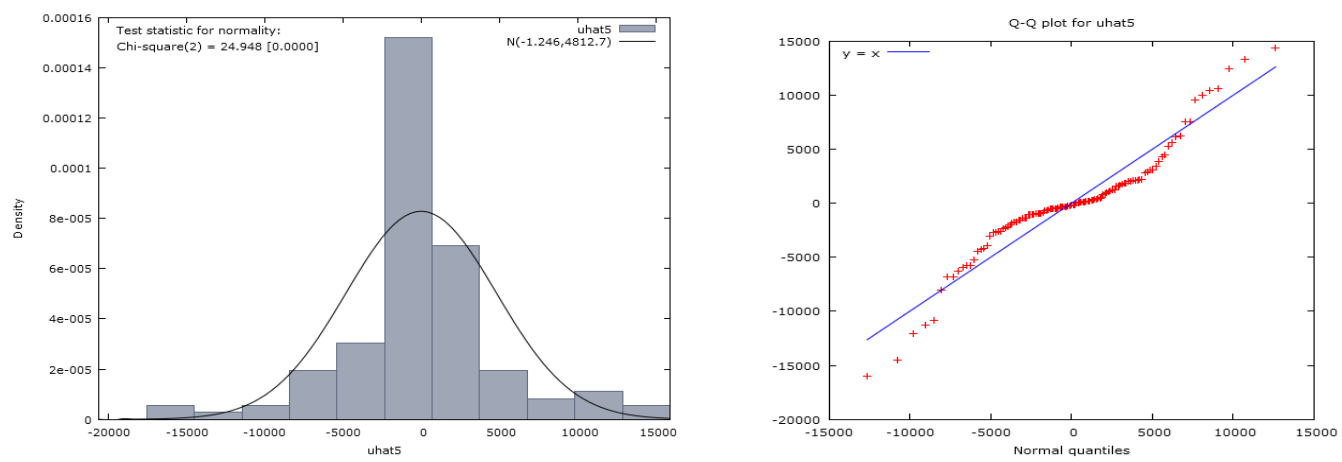

Fig.7 Actual vs. Fitted using arima $(0,1,1)$ model

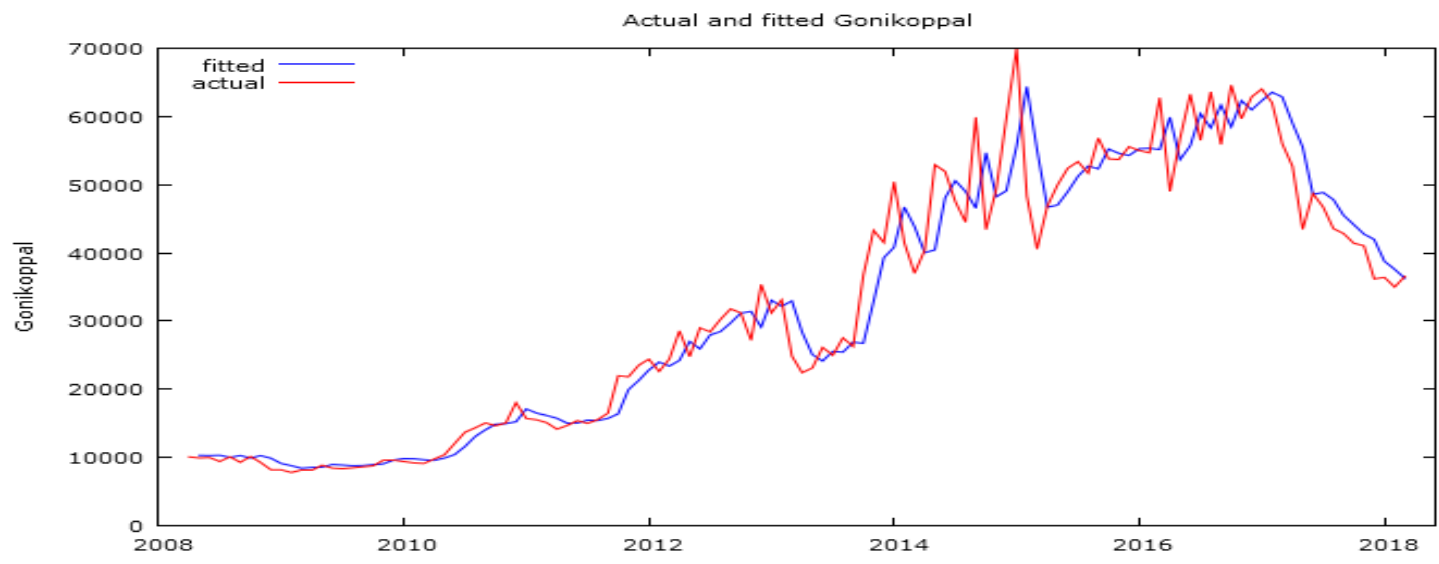

The ARIMA model has a basic assumption that the residuals remain constant over time. Thus, the Heteroscedasticity LM test was carried out to check the volatility or ARCH effect in the time-series. The results of the test are presented in Table 5, which reveals that, there is an $\mathrm{ARCH}$ effect in the time-series.

If the time-series contains ARCH effect, then only we can run the ARCH family models like ARCH, GARCH, EGARCH and TGARCH models. The values of AIC and SBIC for various models are presented in Table 6 . Among the various models, $\mathrm{AR}(1)$ EGARCH $(1,1)$ model is selected as best model based on minimum AIC (18.72) and SBIC (18.86) values. For the selected AR(1)$\operatorname{EGARCH}(1,1)$ model, the parameters with standard error were estimated using MLE and presented in Table 7.

Residual analysis was carried out to check the adequacy of the selected model. The Serial Correlation LM test results are presented in Table 8. The large value of $\mathrm{p}(\mathrm{p}=0.141>0.05)$ w.r.t chi-square statistic reveals that, there is no serial correlation in the residuals. The Normality test results are presented in Table 9. The large value of $p(p=0.681>0.05)$ w.r.t Jarque-Bera statistic indicates that, the residuals are normally distributed.

\section{Comparison of Models}

The accuracy of forecast for the ARIMA $(0,1$, 1) model and AR(1)-EGARCH(1,1) model was tested using test statistic like RMSE and MAPE 
and presented in Table 10. Based on the lowest values of RMSE (4772.10) and MAPE (8.84), the model ARIMA $(0,1,1)$ is found better than AR(1)-EGARCH(1,1) model for Gonikoppal market. The Fig. 7 indicates there were narrow variation between actual prices and predicted prices using ARIMA $(0,1,1)$ model (Verma et. al. 2016) for forecasting of black pepper price in Gonikoppal market. Seyed Jafar Sangsefidi et $a l$. , (2015) also found that the estimation due to ARIMA method has less relative error than the estimation through the ARCH model and the ARIMA model outperformed than ARCH model.

It is concluded that, due to the variety of influence factors and randomness of agricultural product price fluctuation, modeling the market price of agricultural produce can be challenging. In this analysis, it is tried to fit the best model to forecast black pepper price. Among the tested models the prediction accuracy of the ARIMA model is higher than ARCH model by attaining the stationarity in the time-series and also by diagnostic checking. The ARIMA models found better than ARCH models because the monthly price data of black pepper in Gonikoppal market consisting linearity and less volatility. Based on the findings from the study we can propose that ARIMA models are better than ARCH models in predictions of black pepper price. This model could be used to take a decision to a researchers, policymakers and producers to forecast the price of black pepper in Karnataka.

\section{Acknowledgement}

I would like to express my sincere thanks to Dr. Anupriya Paul, Dr. Ajit Paul, Dr. Ashish
Samarpit Noel and Dr. Sudheendra M., members of advisory committee for their valuable and constructive suggestions during the planning and development of this research work.

\section{References}

Bhardwaj, S. P., Ranjit Kumar Paul, Singh, D. R. and Singh, K. N. 2014. An empirical investigation of ARIMA and GARCH models in agricultural price forecasting. Economic Affairs, 59(3): 415-428.

Box, G. E. P., Jenkins, G. M., Reinsel, G. C. and Ljung, G. M., Time Series Analysis: Forecasting and Control, $5^{\text {th }}$ edition, Wiley Publications, 2015.

Fan, J. and Yao, Q., Nonlinear Time Series: Nonparametric and Parametric Methods, Springer, New York, 2003.

Naveena, K. 2016. Statistical modelling for forecasting of price and export of Indian coffee. Ph.D. Thesis, Banaras Hindu University, Varanasi, Uttar Pradesh, India.

Seyed Jafar Sangsefidi, Reza Moghadasi, Saeed Yazdani and Amir Mohamadi Nejad. 2015. Forecasting the prices of agricultural products in Iran with ARIMA and ARCH Models. International Journal of Advanced and Applied Sciences, 2(11): 54-57.

Tsay, L.S., Analysis of Financial Time Series, 2nd ed., Hoboken, N.J: Wiley, 2005.

Verma, V. K., Kumar, P., Singh, S. P. and Singh, H. 2016. Use of ARIMA modeling in forecasting coriander prices for Rajasthan. International Journal of Seed Spices, 6(2): 40-45.

\section{How to cite this article:}

Mallikarjuna, H.B., Anupriya Paul, Ajit Paul, Ashish S. Noel and Sudheendra, M. 2019. Forecasting of Black Pepper Price in Karnataka State: An Application of ARIMA and ARCH Models. Int.J.Curr.Microbiol.App.Sci. 8(01): 1486-1496.

doi: https://doi.org/10.20546/ijcmas.2019.801.159 